\title{
Accessing surgical care for pancreaticoduodenectomy: Patient variation in travel distance and choice to bypass hospitals to reach higher volume centers
}

\author{
Adrian Diaz MD, MPH ${ }^{1,2,3}$ | Sarah Burns BS ${ }^{4}$ Anghela Z. Paredes MD, MS ${ }^{1}$ | \\ Timothy M. Pawlik MD, MPH, $\mathrm{PhD}^{1}{ }^{\mathbb{C}}$
}

${ }^{1}$ Division of Surgical Oncology, The Ohio State University Wexner Medical Center and James Comprehensive Cancer Center, Columbus, Ohio

${ }^{2}$ National Clinician Scholars Program at the Institute for Healthcare Policy and Innovation, University of Michigan, Ann Arbor, Michigan

${ }^{3}$ Center for Healthcare Outcomes and Policy, University of Michigan, Ann Arbor, Michigan

${ }^{4}$ Ohio State University College of Medicine,

Columbus, Ohio

\section{Correspondence}

Timothy M. Pawlik, MD, MPH, PhD, FACS, FRACS (Hon), Professor and Chair,

Department of Surgery, The Urban Meyer III and Shelley Meyer Chair for Cancer Research, Professor of Surgery, Oncology, Health Services Management and Policy, The Ohio State University, Wexner Medical Center, 395W, 12th Ave, Suite 670, Columbus, $\mathrm{OH}$.

Email: tim.pawlik@osumc.edu

Funding information

VA/National Clinician Scholars Program; University of Michigan Institute for Healthcare Policy and Innovation Clinician Scholars Program \& Veterans Affairs Office of Academic Affiliations

\begin{abstract}
Background: While better outcomes at high-volume surgical centers have driven regionalization of complex surgical care, access to high-volume centers often requires travel over longer distances. We sought to evaluate travel patterns of patients undergoing pancreaticoduodenectomy (PD) for pancreatic cancer to assess willingness of patients to travel for surgical care.

Methods: The California Office of Statewide Health Planning database was used to identify patients who underwent PD between 2005 and 2016. Total distance traveled, as well as whether a patient bypassed the nearest hospital that performed PD to get to a higher-volume center was assessed. Multivariate analyses were used to identify factors associated with bypassing a local hospital for a higher-volume center. Results: Among 23014 patients who underwent PD, individuals traveled a median distance of 18.0 miles to get to a hospital that performed PD. The overwhelming majority (84\%) of patients bypassed the nearest providing hospital and traveled a median additional 16.6 miles to their destination hospital. Among patients who bypassed the nearest hospital, 13,269 (68.6\%) did so for a high-volume destination hospital. Specifically, average annual PD volume at the nearest "bypassed" vs final destination hospital was 29.6 vs 56 cases, respectively. Outcomes at bypassed vs destination hospitals varied (incidence of complications: $39.2 \%$ vs $32.4 \%$; failure-to-rescue: $14.5 \%$ vs 9.1\%). PD at a high-volume center was associated with lower mortality ( $O R=0.4695 \%$ $\mathrm{Cl}, 0.22-0.95$ ). High-volume PD ( $>20$ cases) was predictive of hospital bypass ( $\mathrm{OR}=3.8$ $95 \% \mathrm{Cl}, 3.3-4.4)$. Among patients who had surgery at a low-volume center, nearly $20 \%$ bypassed a high-volume hospital in route. Furthermore, among patients who did not bypass a high-volume hospital, one-third would have needed to travel only an additional 30 miles or less to reach the nearest high-volume hospital.
\end{abstract}

Conclusion: Most patients undergoing PD bypassed the nearest providing hospital to seek care at a higher-volume hospital. While these data reflect increased regionalization of complex surgical care, nearly 1 in 5 patients still underwent PD at a low-volume center.

KEYWORDS

access, pancreaticoduodenectomy, surgery, travel 


\section{1 | INTRODUCTION}

Americans face an increasing and diverse number of barriers to access healthcare. Potential barriers include insurance status, health literacy, and cost, all of which have been extensively examined. ${ }^{1-3}$ Another less studied barrier is the distance needed to travel to obtain care. ${ }^{4,5}$ Specifically, with increased emphasis on centralization of healthcare networks and particularly surgical services, rural hospitals are at an increased risk of foreclosure. ${ }^{6-10}$ While the number of major surgical hospitals increased over the decade from 2005 to 2015 , there was an $82 \%$ increase in the number of people who lived further than an hour from any hospital, let alone a highvolume surgical center. ${ }^{4}$ In fact, up to $10 \%$ of the United States population resides outside a 30 mile radius of a hospital with the capacity to perform adult inpatient surgery. ${ }^{5}$ While access to surgical services has been examined through the lens of insurance, race, and health literacy, the relationship of travel distance to access, in the context of surgical cancer care, has only more recently become an area of closer focus. ${ }^{11,12}$

Surgical services are a large part of curative-intent therapy for patients with cancer. High-volume surgical centers have lower morbidity and mortality compared with low-volume centers, especially among patients undergoing more complex and high-risk cancerrelated surgical procedures. ${ }^{13-15}$ These high-volume centers are often located, however, in urban areas, which compounded by the closure of existing rural hospital-based surgical services, may hinder rural community access to high-quality surgical care. ${ }^{13,15-17}$ For example, although the number of hospitals that provided surgical services with an approved American College of Surgeons (ACS) cancer program slightly increased since 2005 , the number of people living greater than 60 minutes has increased from $6 \%$ to $11 \%{ }^{18}$

The call to centralize complex surgical procedures, including operations associated with cancer treatment, to high-volume centers has the potential to create a significant barrier of increased travel burden on potentially vulnerable populations. ${ }^{16,19}$ Understanding the characteristics of patients and travel burden experienced by individuals who must travel to receive surgical cancer care is, therefore, important. The objective of the current study was to characterize travel patterns among patients who underwent pancreaticoduodenectomy (PD) for cancer. In particular, we sought to determine the travel distance burden among patients undergoing PD, as well as examine whether patients were likely to bypass a closer hospital that performed PD to access a different center.

\section{2 | METHODS}

\section{1 | Data and study population}

A cohort analysis of the California Office of State-wide Health Planning and Development ${ }^{20}$ (OSHPD) hospital discharge database from 2005 to 2016 was performed. As a department within the California Health and Human Services Agency, the OSHPD oversees the collection and dissemination of healthcare information from licensed practitioners and hospitals within California, resulting in complete capture of all hospital stays for California patients. The data were appropriately deidentified with encrypted ID assignments.

The International Classification of Diseases, ninth and tenth Revision (ICD-9 and ICD10) diagnosis and procedure codes were utilized to define the population of interest. Specifically, patients with a diagnosis of pancreatic, duodenal, or biliary neoplasm (See Appendix 1 for ICD codes) who underwent a PD (See Appendix 1 for ICD codes) were included in the analytic cohort $(n=23014)$. Patient-specific variables selected for analysis included age, race/ ethinicity, sex, and insurance type. Hospital variables included teaching hospital status, number of beds, number of operating rooms, and annual PD hospital volume and in-hospital all-cause mortality for PD. Outcomes of interest were total real driving distance traveled to reach destination hospitals, as well as the incidence of patients who bypassed a hospital that performed PD to reach a different center that performed PD surgery.

\section{2 | Geospatial analysis}

Data were imported into QGIS 2.18 statistical package for geospatial analysis (QGIS Development Team, 2009. QGIS Geographic

TABLE 1 Patient and hospital level characteristics for patients undergoing pancreaticoduodenectomy, 2005-2016

\begin{tabular}{|c|c|c|}
\hline \multicolumn{3}{|l|}{ Patient characteristics $(\mathrm{N}=23014)$} \\
\hline Median distance traveled (Miles) (IQR) & 18.0 & $7.6-42.0$ \\
\hline Bypassed nearest providing hospital (\%) & 19327 & $83.9 \%$ \\
\hline Age (Mean) [SD] & 65.54 & 11.37 \\
\hline \multicolumn{3}{|l|}{ Sex } \\
\hline Male & 12026 & $52.3 \%$ \\
\hline Female & 10988 & $47.7 \%$ \\
\hline \multicolumn{3}{|l|}{ Race (\%) } \\
\hline White & 14505 & $63.0 \%$ \\
\hline African American & 1294 & $5.6 \%$ \\
\hline Hispanic & 3738 & $16.2 \%$ \\
\hline Asian & 2632 & $11.4 \%$ \\
\hline Other & 845 & $3.7 \%$ \\
\hline \multicolumn{3}{|l|}{ Insurance (\%) } \\
\hline Self pay & 289 & $1.3 \%$ \\
\hline Medicaid & 1796 & $7.8 \%$ \\
\hline Medicare & 11902 & $51.7 \%$ \\
\hline Private & 8536 & $37.1 \%$ \\
\hline Other & 289 & $1.3 \%$ \\
\hline \multicolumn{3}{|l|}{ Destination hospital characteristics $(n=189)$} \\
\hline Annual procedure volume (mean SD) & 10.17 & 20.7 \\
\hline High volume ( > 20 PD per y) & 14510 & 63.05 \\
\hline In-hospital mortality rate (mean SD) & 3.7 & 0.19 \\
\hline LOS (days) (mean SD) & 15.16 & 12.08 \\
\hline Charge \$USD (mean SD) & 220496 & 265755 \\
\hline Total admissions (mean SD) & 21335.87 & 9398.36 \\
\hline Total beds (mean SD) & 432.58 & 191.87 \\
\hline Total operating rooms (mean SD) & 25.58 & 11.47 \\
\hline Academic Medical Center (Total, \%) & 17803 & 77.36 \\
\hline Full time nurses (mean SD) & 1404.1 & 674.37 \\
\hline
\end{tabular}

Abbreviations: LOS, length-of-stay; PD, pancreaticoduodenectomy. 
TABLE 2 Unadjusted comparison of patient and hospital characteristics based on hospital bypass status

\begin{tabular}{|c|c|c|c|c|c|}
\hline \multirow[b]{2}{*}{ Median miles traveled (IQR) } & \multicolumn{2}{|c|}{ Nearest hospital $(n=3687$ ) } & \multicolumn{2}{|c|}{ Bypassed hospital ( $n=19327$ ) } & \multirow{2}{*}{$\begin{array}{l}P \\
<.001\end{array}$} \\
\hline & 4.72 & 2.91-11.44 & 21.34 & $10.04-49.18$ & \\
\hline Age & 67.07 & $66.71-67.43$ & 65.25 & $65.09-65.41$ & $<.001$ \\
\hline \multicolumn{6}{|l|}{ Race } \\
\hline White & 2412 & $65.4 \%$ & 12093 & $62.6 \%$ & $<.001$ \\
\hline Black & 235 & $6.3 \%$ & 1059 & $5.5 \%$ & \\
\hline Hispanic & 575 & $15.6 \%$ & 3163 & $16.3 \%$ & \\
\hline Asian & 337 & $9.1 \%$ & 2295 & $11.9 \%$ & \\
\hline Other & 128 & $4.4 \%$ & 717 & $3.7 \%$ & \\
\hline \multicolumn{6}{|l|}{ Sex } \\
\hline Male & 4380 & $51.4 \%$ & 7665 & $52.7 \%$ & $<.001$ \\
\hline Female & 4136 & $48.6 \%$ & 6877 & $47.3 \%$ & \\
\hline \multicolumn{6}{|l|}{ Insurance } \\
\hline Self pay & 43 & $1.2 \%$ & 246 & $1.3 \%$ & $<.001$ \\
\hline Medicaid & 281 & $7.6 \%$ & 1515 & $7.9 \%$ & \\
\hline Medicare & 2136 & $57.9 \%$ & 9766 & $51.0 \%$ & \\
\hline Private & 1176 & $31.9 \%$ & 7360 & $38.5 \%$ & \\
\hline Other & 51 & $1.4 \%$ & 246 & $1.3 \%$ & \\
\hline \multicolumn{6}{|l|}{ Destination hospital characteristics } \\
\hline Annual procedure volume (mean SD) & 29.57 & $28.29-30.84$ & 55.99 & $55.35-56.62$ & $<.001$ \\
\hline High volume ( > 20 PD per y) & $33.7 \%$ & $32.13-35.18$ & $68.6 \%$ & $68.0-69.31$ & \\
\hline In-hospital mortality rate (mean SD) & $6.08 \%$ & $5.30-6.84$ & $3.21 \%$ & $2.96-3.46$ & $<.001$ \\
\hline LOS (days) & 17.1 & $16.65-17.46$ & 14.8 & 14.63-14.97 & $<.001$ \\
\hline Charge (\$USD) & 229951.70 & $221595-238308$ & 218692 & $214927-222457$ & .0184 \\
\hline Complication & $39.2 \%$ & $37.59-40.74$ & $32.4 \%$ & $31.69-33.01$ & $<.001$ \\
\hline Failure to rescue & $14.47 \%$ & $12.66-16.29$ & $9.1 \%$ & $8.43-9.86$ & $<.001$ \\
\hline Academic medical center & $60.4 \%$ & $58.77-61.93$ & $80.6 \%$ & $80.04-81.16$ & $<0.001$ \\
\hline Total admissions & 18956 & $18628-19284$ & 21774 & $21640-21908$ & $<.001$ \\
\hline Total beds & 371.52 & $365.01-378.04$ & 443.83 & $441.09-446.57$ & $<.001$ \\
\hline Total operating rooms & 20.9 & $20.48-21.37$ & 26.4 & $26.20-26.55$ & $<.001$ \\
\hline Full time RN & 1120.1 & $1091.16-1148.98$ & 1449.6 & $1439.03-1460.13$ & $<.001$ \\
\hline
\end{tabular}

Abbreviations: LOS, length-of-stay; PD, pancreaticoduodenectomy.

Information System. Open Source Geospatial Foundation). Hospitals were geocoded using the reported address. Using OpenStreetMaps road and traffic data and osm2po routing engine, travel distances were calculated to each hospital. ${ }^{21}$ The nearest hospital assigned to each patient was determined by the shortest driving distance between the patient's corresponding residential zip code and a given hospital location. Patients were defined as bypassing the nearest providing facility if the actual travel distance surpassed the shortest calculated travel distance. Differential distance was then calculated as the difference in distance between the destination and nearest hospitals.

\section{3 | Statistical methods}

Unadjusted analyses were performed for comparison of patients who did and did not bypass a hospital for PD using $\chi^{2}$ and $\mathrm{t}$ test for categorical and continuous variables, respectively. Multivariate analysis was utilized to identify factors associated with bypassing a hospital while controlling for patient demographics, hospital teaching status, PD volume, as well as mortality of the destination hospital. All statistical analyses were performed using Stata statistical software version 16 (College Station, TX). All tests were two-sided, and $P$ values of less than .05 were considered to indicate statistical significance.

\section{3 | RESULTS}

Among the 23014 patients who underwent PD for a neoplasm of the pancreas, duodenum, or bile duct in California between 2005 and 2016, mean patient age was 65 years and roughly one-half $(52.3 \%)$ of patients were male. The majority of patients were White (63\%), followed by Hispanic (16.2\%), Asian (11.4\%), and African American (5.6\%). Half the cohort was insured by Medicare (51.7\%), whereas other patients had private insurance (37.1\%), Medicaid (7.8\%), or were self-pay (1.3\%). Among the 189 hospitals that performed PD, overall mean annual PD volume was 10; 23 hospitals were identified as high-volume centers, defined using the Leap Frog criteria as an average annual PD volume $>20$ (Table 1). ${ }^{22}$ Roughly two-thirds of patients $(n=14510,63.1 \%)$ underwent PD at a highvolume center. Following PD, overall mean length-of-stay (LOS) was 15.2 days (IQR 8.0-17.0) (low-volume centers: mean LOS, 17.0 days vs high-volume center: mean LOS, 14.1 days) with a 30-day mortality of $3.7 \%$ (low-volume centers: in hospital mortality, $5.9 \%$ vs high-volume centers: in hospital mortality, 2.4\%) (both $P<.05$ ). Mean number of hospital beds was 432.6 (low-volume: 295.9 vs high-volume: 500.8), mean number of operating rooms 25.6 (lowvolume: 16.2 vs high-volume: 29.1), and most hospitals (77.4\%) 
TABLE 3 Multivariable analysis of patient and hospital characteristics as predictors for bypassing nearest providing hospital

\begin{tabular}{|c|c|c|c|}
\hline & OR & $95 \% \mathrm{Cl}$ & $P$ \\
\hline Total distance traveled & 3.46 & $3.27-3.67$ & $<.001$ \\
\hline Age & 0.99 & $0.98-0.99$ & $<.001$ \\
\hline $\begin{array}{l}\text { Race/Ethnicity } \\
\text { White } \\
\text { African American } \\
\text { Hispanic } \\
\text { Asian }\end{array}$ & $\begin{array}{l}\text { Ref } \\
1.28 \\
1.53 \\
1.86\end{array}$ & $\begin{array}{l}1.02-1.60 \\
1.31-1.79 \\
1.57-2.21\end{array}$ & $\begin{array}{l}<.001 \\
<.001 \\
<.001\end{array}$ \\
\hline $\begin{array}{l}\text { Sex } \\
\qquad \text { Male } \\
\text { Female }\end{array}$ & $\begin{array}{l}\text { Ref } \\
0.94\end{array}$ & $0.85-1.05$ & .262 \\
\hline $\begin{array}{l}\text { Insurance } \\
\text { Medicare } \\
\text { Medicaid } \\
\text { Private } \\
\text { Self pay } \\
\text { Other }\end{array}$ & $\begin{array}{l}\text { Ref } \\
1.15 \\
0.99 \\
1.26 \\
1.29\end{array}$ & $\begin{array}{l}0.91-1.44 \\
0.86-1.16 \\
0.82-1.95 \\
0.85-1.94\end{array}$ & $\begin{array}{l}.236 \\
.989 \\
.293 \\
.234\end{array}$ \\
\hline In-hospital mortality & 1.06 & $0.83-1.37$ & .626 \\
\hline Complications & 0.98 & $0.87-1.10$ & .756 \\
\hline High volume ( $>20$ cases) & 3.82 & $3.31-4.41$ & $<.001$ \\
\hline Charge & 1.00 & $0.99-1.00$ & .485 \\
\hline Academic medical center & 1.13 & $0.99-1.30$ & .077 \\
\hline Total admission & 1.00 & $0.99-0.99$ & $<.001$ \\
\hline Total beds & 1.00 & $1.00-1.00$ & $<.001$ \\
\hline Total operating rooms & 1.00 & $0.99-1.01$ & .674 \\
\hline Full time RN & 1.00 & 0.99-0.99 & $<.001$ \\
\hline
\end{tabular}

were academic medical centers (low-volume: $52.5 \%$ vs high-volume: 91.9\%) (all $P<.05$ ).

Comparing travel patterns among patients undergoing PD, 3687 (16.0\%) patients underwent surgery at the nearest hospital available whereas 19327 (84.0\%) patients bypassed the nearest hospital to travel to a different center (Table 2). On average, patients traveled 18.0 (IQR: 7.64-42.00) miles to the hospital at which PD was performed (final destination low-volume hospital: 10.8 miles vs final destination high-volume hospital: 23.5 miles) (Table 1). Specifically, among patients who bypassed a closer hospital, 13269 (68.6\%) individuals underwent PD at a high-volume center vs 6058 (31.34\%) patients who had a PD at a low-volume center $(P<.05)$. Patients who underwent $P D$ at the nearest hospital had a median travel distance of 4.7 miles vs a travel distance of 21.3 miles among patients who bypassed the closest hospital to undergo PD at a more distant center $(P<.05)$. Of note, the annual PD volume at closer hospitals vs destination hospitals was considerably lower (29.6 vs 56.0 , respectively) $(P<.05)$. The odds of undergoing PD at a high-volume hospital was higher among patients who had bypassed the nearest hospital (OR, 3.82, 95\% Cl, 3.31-4.41) (Table 3).

Compared with the nearest hospital, destination PD hospitals were likely to be academic medical centers (nearest: $60.4 \%$ vs destination: $80.6 \%$ ), had more mean annual admissions (nearest:
21,774 vs destination: 18 956), more hospital beds (nearest: 372 vs destination: 444), more operating rooms (nearest: 21 vs destination: 26.4), as well as more full time nurses (nearest: 1120 vs destination: 1450) (all $P<.05$ ) (Table 2). In turn, peri-operative morbidity (nearest: $32.4 \%$ vs destination: $39.2 \%)$, failure-to-rescue (nearest: $14.5 \%$ vs destination: $9.1 \%$ ), as well as mortality (nearest: $6.1 \%$ vs destination: $3.2 \%$ ) were all lower among patients who had bypassed a closer hospital to travel to a further destination hospital that performed PD (all $P<.05$ ). Of note, among a subset analysis of 8503 patients who underwent PD at a low-volume hospital, 1459 (17.2\%) patients had actually bypassed a high-volume hospital to have surgery at a low-volume center. In this subset of patient, there was no difference in the distance traveled among Medicare beneficiaries and privately insured patients (54.7 vs 50.4 miles); Medicaid beneficiaries (33.6 miles, $P<.001$ ) traveled shorter distances. Among the 7044 individuals who did not bypass a high-volume hospital, roughly one-third ( $n=2379,33.8 \%$ ) would have needed to travel an additional 30 miles or less to reach the nearest high-volume hospital; 922 (13.1\%) patients would have needed to travel an additional 100 miles or greater to reach the nearest high-volume hospital (Table 4).

On multivariable analysis, African American (OR, 1.28, $95 \% \mathrm{Cl}$, 1.02-1.60), Hispanic (OR, $1.5395 \% \mathrm{Cl}, 1.31-1.79)$, and Asian (OR, $1.86,95 \% \mathrm{Cl}, 1.57-2.21$ ) patients were more likely to have bypassed the nearest hospital to go to a different center. Among African American, Hispanic, and Asian patients who did bypass a closer hospital, more than half $(59.8 . \%, 61.2 \%$, and $68.4 \%)$ bypassed a lowvolume center to go to high-volume center for PD. However, roughly 1 in 3 African American (40.2\%), Hispanic (38.8\%), and Asian (31.8\%) patients bypassed a closer hospital to undergo PD simply at a different low-volume hospital. Of note, age, sex, or insurance type were not associated with odds of a patient bypassing the nearest hospital (all $P>.05$ ).

\section{4 | DISCUSSION}

Access to high-quality inpatient oncologic surgical services is a major population health priority. Access to care may be limited by a number of factors including, but not limited to, insurance status, ability to pay, availability of hospital/provider, and ability to take time off from work. While travel time and distance may also impact access to subspecialty, complex surgical services, this topic has not been wellstudied. The current study was important because we specifically examined both travel distance, as well as the incidence of bypassing closer hospitals, to receive PD surgery. In particular, unlike previous studies, true travel distance was assessed using geocoding software and traffic data. Of note, among the over 23000 patients who underwent PD in California between 2005 and 2016, 84\% bypassed the closest hospital to their home to travel a median distance of 18 miles for surgery (Figure 1). While the odds of undergoing PD at a high-volume hospital was higher among patients who had bypassed the nearest hospital, a significant number of patients who bypassed a closer hospital still underwent PD at a low-volume hospital. In fact, 
TABLE 4 Patient characteristics for patients undergoing pancreaticoduodenectomy at low-volume hospitals

\begin{tabular}{|c|c|c|c|c|c|c|c|}
\hline \multicolumn{8}{|l|}{ Patient characteristics ( $N=8503$ ) } \\
\hline \multicolumn{3}{|l|}{ Bypassed high-volume hospital (\%) } & \multicolumn{3}{|c|}{1459} & \multicolumn{2}{|r|}{17.2} \\
\hline \multicolumn{3}{|l|}{ Median Miles traveled (IQR) } & \multicolumn{3}{|c|}{6.89} & \multicolumn{2}{|r|}{$2.50-13.35$} \\
\hline \multicolumn{3}{|c|}{ Did not bypass high-volume hospital (\%) } & \multicolumn{2}{|c|}{7044} & & \multicolumn{2}{|r|}{82.8} \\
\hline \multicolumn{2}{|l|}{ Median additional miles HVH (IQR) } & & \multicolumn{2}{|c|}{56.76} & & \multicolumn{2}{|r|}{$15.78-82.38$} \\
\hline Range of additional miles traveled & $<30$ & & $30-100$ & & $>100$ & & Total \\
\hline Total (\%) & 2379 & (33.8) & 3743 & $(53.1)$ & 922 & $(13.1)$ & 7044 \\
\hline Age (mean) $[S D]$ & 66.00 & $(10.9)$ & 65.82 & (11.07) & 66.05 & $(11.11)$ & \\
\hline \multicolumn{8}{|l|}{ Sex } \\
\hline Male & 1225 & (33.7) & 1958 & $(53.9)$ & 451 & $(12.4)$ & 3634 \\
\hline Female & 1154 & (33.8) & 1785 & $(52.35)$ & 471 & $(13.8)$ & 3410 \\
\hline \multicolumn{8}{|l|}{ Race } \\
\hline White & 1308 & (30.3) & 2352 & $(54.4)$ & 664 & (15.4) & 4324 \\
\hline African American & 162 & (33.7) & 275 & $(57.2)$ & 44 & $(9.2)$ & 481 \\
\hline Hispanic & 588 & $(44.5)$ & 595 & $(45.0)$ & 138 & $(10.5)$ & 1321 \\
\hline Asian & 256 & (35.3) & 407 & $(56.1)$ & 62 & (8.6) & 725 \\
\hline Other & 65 & (33.7) & 114 & $(59.1)$ & 14 & (7.3) & 193 \\
\hline \multicolumn{8}{|l|}{ Insurance } \\
\hline Self pay & 25 & $(28.4)$ & 55 & $(62.5)$ & 8 & (9.1) & 88 \\
\hline Medicaid & 245 & (37.9) & 332 & $(51.4)$ & 69 & $(10.7)$ & 646 \\
\hline Medicare & 1218 & $(32.6)$ & 2020 & $(54.0)$ & 501 & (13.4) & 3739 \\
\hline Private & 860 & (35.6) & 1229 & $(50.8)$ & 329 & $(13.6)$ & 2418 \\
\hline Other & 31 & (20.3) & 107 & $(69.9)$ & 15 & $(9.8)$ & 153 \\
\hline
\end{tabular}

nearly $20 \%$ of patients actually bypassed a high-volume hospital in route to have surgery at a low-volume center. Furthermore, among patients who did not bypass a high-volume hospital, one-third would have needed to travel only an additional 30 miles or less to reach the nearest high-volume hospital (Figure 2).

Data from the current study demonstrated that patients were indeed willing to travel longer distances and bypass closer hospitals to receive certain types of complex medical care such as PD. Interestingly, these data differed from other studies that had suggested that patients preferred to seek medical care closer to their home. ${ }^{23,24}$ The reason for these disparate results was undoubtedly multifactorial and may have been related to differences in surgical procedures being considered. For example, patients may prefer to seek medical care, as well as be referred to local surgeons, for certain operations generally considered lower risk (eg, distal gastrectomy and colectomy). ${ }^{23,24}$ In contrast, complex surgical procedures such as PD that involve more potential morbidity and mortality may often cause local physicians to refer patients to regional high-volume centers. ${ }^{25}$ In addition, patients may self-select more experienced centers when faced with a disease that requires more specialized surgical care. ${ }^{26}$ While local referrals to low-cost hospitals for some procedures may be associated with acceptable morbidity and mortality, referral to high-volume centers may provide more value for other types of complex operations. ${ }^{25,27,28}$ Regionalization of care can, however, force patients to travel longer distances. To this point, patients who underwent PD at the nearest hospital had a median travel distance of 4.7 miles vs a travel distance of 21.3 miles among patients who bypassed the closest hospital to undergo PD at a more distant center. Perhaps of even more interest was the finding that a large subset of patients actually traveled past a closer high-volume hospital ultimately to undergo PD at a lowvolume center. Specifically, this phenomenon was most pronounced among underrepresented minority patients as roughly 1 in 3 African American, Hispanic, and Asian patients bypassed a closer hospital to undergo PD simply at a different low-volume hospital. Of note, other investigators have similarly noted that some patients may have a tendency to travel beyond high-volume centers in favor of seeking surgery at low-volume hospitals, despite a higher chance of surgeryrelated mortality at these centers. ${ }^{19,29}$ Patients willingness to travel for higher level of care can improve both short- and long-term outcomes, especially for patients with complex diseases such as liver and pancreatic cancer. ${ }^{30-32}$ The decision to where to have ones complex oncologic operation is certainly a complex one. While we have shown that patients are willing to travel longer distances for their PD operation, there are several unmeasured variables that may also be influencing a patients decision to travel further. For example, a patients' relationships with previous providers matter a great deal and therefore referral patterns would certainly have a major influence as to where patients may ultimately choose to have their operation. In addition, a patients insurance and more importantly whether a hospital or provider is covered by the patients insurance provider will more likely than not play a large role in the patients decision to where to have surgery. Hospital systems, and insurance networks are in the unique position to centralize care so that their patients can receive their operation at the hospital that offers the greatest chance at a good outcome with the highest value. 


\section{Mean Miles Traveled}

\section{No Data $<25$ \\ $25-35$ \\ $35-50$ \\ $50-70$ \\ $>70$}

$\oplus$ High Volume Hospital

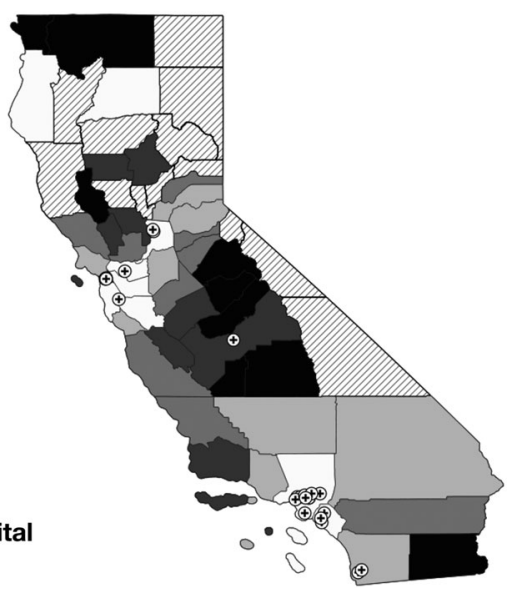

FIGURE 1 Total patient travel distance to reach destination hospitals to undergo PD by California County

The volume-outcome relationship related to complex surgical procedures has been well-documented. ${ }^{13-15}$ In the current centers, it was interesting to note that destination PD hospitals were likely to be academic medical centers, had more mean annual admissions, more hospital beds, more operating rooms, as well as more full time nurses (Table 2). In aggregate, patients who bypassed a closer hospital to be treated at a destination had lower peri-operative morbidity and failure-to-rescue, as well as an incidence of perioperative mortality that was almost one-half lower. Previous work from our group and others have demonstrated that high-volume centers, especially centers with a teaching designation, have improved outcomes associated with high-risk surgical procedures. ${ }^{33}$ For example, Hyder et $\mathrm{al}^{34}$ noted that quality metrics such as lengthof-stay and mortality following complex hepatopancreaticobiliary surgery were also better at high-volume academic medical centers. Our group has previously characterized the association between travel distance and hospital volume relative to outcomes following resection of cholangiocarcinoma, gallbladder cancer, and hepatocellular carcinoma. ${ }^{35-38}$ Both increasing travel distance and hospital volume were associated with improved overall survival; however, adjusted models demonstrated that the impact of travel distance was largely mediated through hospital volume. Collectively, the data strongly suggest that bypassing a closer hospital to travel to a destination hospital that is higher volume should generally be encouraged for patients seeking PD as surgical treatment.

While longer travel distances may translate into more patients receiving surgical care at high-volume regional centers, other aspects of the multimodality care of the cancer patient also need to be considered. For example, Idrees et $\mathrm{al}^{39}$ reported that centralization of surgery for cholangiocarcinoma to high-volume hospitals increased compliance with National Comprehensive Cancer Network guidelines. Other studies, however, have suggested that longer travel distances can impede a patients ability to receive other nonsurgical therapies. For example, patients with prostate cancer in both urban and rural settings were less likely to receive radiation therapy rather than surgery the farther away they lived from a treatment center. These findings raise the possibility that the geographic availability of radiation treatment centers may be an important determinant of whether patients are able to choose radiation rather than surgery for localized prostate cancer. ${ }^{40}$ In a different study, Lin et $\mathrm{al}^{41}$ reported that increased travel burden was associated with a decreased likelihood of receiving adjuvant chemotherapy. In addition, increased travel burden may also be associated with decreased likelihood of receiving adjuvant radiation therapy for a variety of cancers. ${ }^{42}$ Of note, the travel distance burden may affect vulnerable populations disproportionately. For example, among patients undergoing pancreatectomy, the elderly, racial minorities, and patients with self-pay or Medicaid payer status were most sensitive to travel burden. ${ }^{14}$ Access to comprehensive oncologic care at major cancer programs is important because delays in treatment may lead to worse oncologic outcomes. ${ }^{43-45}$

Several limitations should be considered when interpreting the results. While the California database allowed for $100 \%$ capture with
FIGURE 2 Total distance to nearest high-volume center for patients who underwent surgery at a low-volume center
Bypassed HVH

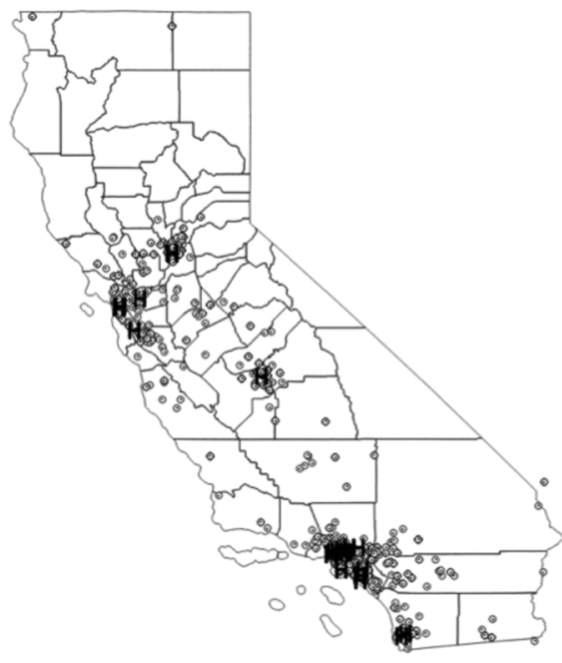

H - High Volume Hospital $\odot$ Bypassed HVH
Did not bypassed HVH

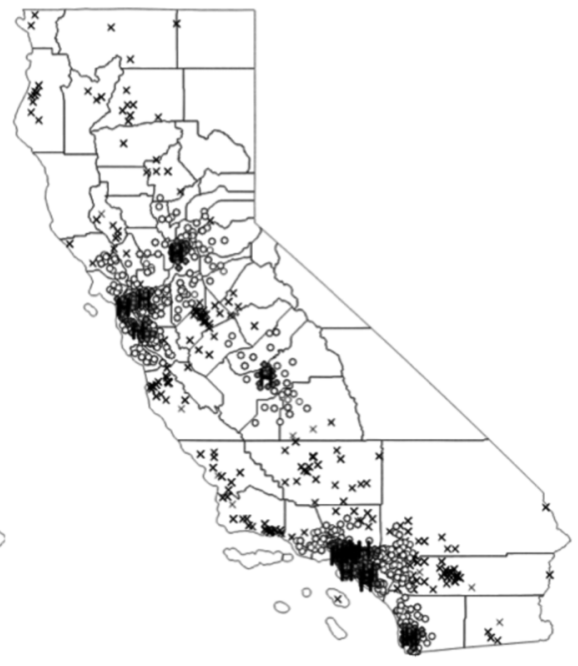

$<30$ miles

30-100 miles
$X>100$ miles 
complete evaluation of travel for all patients receiving surgery at California-licensed facilities, the data were limited to one state and therefore the data may not be generalizable to other geographically distinct states. While possible reasons for traveling could include personal preferences, level of education, financial constraints for both medical and nonmedical expenses, or referral practices of diagnosing providers, we were not able to define specific reasons why patients did or did not bypass a hospital or travel further distances. For example, an important missing variable is patient income, which would likely affect a patient's ability and tolerance for increased travel. Volume and mortality data were also analyzed at the hospital level, thus making it difficult to understand how patient travel decisions were influenced by individual surgeon outcomes. Finally, the California state database lacked certain cancer-specific information and therefore we were not able to examine if and where patients received chemotherapy or other cancer-specific treatments.

In conclusion, most patients undergoing PD bypassed the nearest providing hospital to seek care at a higher-volume hospital. While the data demonstrated increased regionalization of complex surgical care, nearly 1 in 5 patients still underwent PD at a low-volume center. Importantly, nearly half of patients who had PD at a lowvolume center could have undergone surgery at a high-volume center with minimal increase in travel burden. These data would support the facilitation of patient travel to destination high-volume centers for patients in need of PD. Such data support employer-based plans that offer employees the opportunity to receive care at regional centers of excellence with no additional personal travel cost. ${ }^{46,47}$

\section{CONFLICT OF INTERESTS}

The authors of this study have no conflict of interests to report.

\section{FUNDING INFORMATION}

Dr. Diaz received salary support from the Veterans Affairs Office of Academic Affiliations during the time of the study

\section{DATA AVAILABILITY STATEMENT}

The data that support the findings of this study are available in California's Office of Statewide Health Planning and Development at https://oshpd.ca.gov/data-and-reports/request-data/

\section{ORCID}

Timothy M. Pawlik (iD http://orcid.org/0000-0002-7994-9870

\section{REFERENCES}

1. Levy $H$, Janke A. Health literacy and access to care. J Health Commun. 2016;21(Suppl 1):43-50. https://doi.org/10.1080/10810730 2015.1131776
2. Schoen C, Osborn R, Squires D, Doty MM. Access, affordability, and insurance complexity are often worse in the United States compared to ten other countries. Health Aff Proj Hope. 2013;32(12):2205-2215. https://doi.org/10.1377/hlthaff.2013.0879

3. Collins SR, Gunja MZ, Doty MM, Beutel S Americans' Experiences with ACA Marketplace and Medicaid Coverage: Access to Care and Satisfaction. http://www.commonwealthfund.org/publications/issuebriefs/2016/may/aca-tracking-survey-access-to-care-andsatisfaction. Published May 25, 2016. Accessed April 20, 2017.

4. Diaz A, Schoenbrunner A, Pawlik TM. Trends in the geospatial distribution of inpatient adult surgical services across the United States. Ann Surg. 2019. https://doi.org/10.1097/SLA.0000000000003366

5. Diaz A, Schoenbrunner A, Cloyd J, Pawlik TM. Geographic distribution of adult inpatient surgery capability in the USA. J Gastrointest Surg Off J Soc Surg Aliment Tract. 2019;23(8):1652-1660. https://doi. org/10.1007/s11605-018-04078-9

6. Chhabra KR, Dimick JB. Strategies for improving surgical care: When is regionalization the right choice? JAMA Surg. 2016;151(11):10011002. https://doi.org/10.1001/jamasurg.2016.1059

7. Ellison EC, Pawlik TM, Way DP, Satiaini B, Williams TE. The impact of the aging population and incidence of cancer on future projections of general surgical workforce needs. Surgery. 2017;163(3):553-559. https://doi.org/10.1016/j.surg.2017.09.035

8. Pfuntner A, Wier LM, Stocks C. Most frequent procedures performed in U.S. hospitals, 2011: statistical Brief \#165. Healthcare Cost and Utilization Project (HCUP) Statistical Briefs. Rockville (MD): Agency for Healthcare Research and Quality (US); 2006. http:// www.ncbi.nlm.nih.gov/books/NBK174682/ Accessed November 24, 2017.

9. Williams TE, Ellison EC. Population analysis predicts a future critical shortage of general surgeons. Surgery. 2008;144(4):548-554. https:// doi.org/10.1016/j.surg.2008.05.019. discussion 554 to 556 .

10. Young J, Thompson A, Tait I, Waugh L, McPhillips G. Centralization of services and reduction of adverse events in pancreatic cancer surgery. World J Surg. 2013;37(9):2229-2233. https://doi.org/10. 1007/s00268-013-2108-4

11. Zogg CK, Scott JW, Jiang W, Wolf LL, Haider AH. Differential access to care: the role of age, insurance, and income on race/ethnicityrelated disparities in adult perforated appendix admission rates. Surgery. 2016;160(5):1145-1154. https://doi.org/10.1016/j.surg. 2016.06.002

12. De Oliveira GS, McCarthy RJ, Wolf MS, Holl J. The impact of health literacy in the care of surgical patients: a qualitative systematic review. BMC Surg. 2015;86:15. https://doi.org/10.1186/s12893-0150073-6

13. Finks JF, Osborne NH, Birkmeyer JD. Trends in hospital volume and operative mortality for high-risk surgery. N Engl J Med. 2011; 364(22):2128-2137. https://doi.org/10.1056/NEJMsa1010705

14. Fong ZV, Loehrer AP, Fernández-Del Castillo C, et al Potential impact of a volume pledge on spatial access: a population-level analysis of patients undergoing pancreatectomy. Surgery. 2017;162(2):203-210. https://doi.org/10.1016/j.surg.2017.03.010

15. Xu Z, Becerra AZ, Justiniano CF, et al Is the distance worth It? Patients with rectal cancer traveling to high-volume centers experience improved outcomes. Dis Colon Rectum. 2017;60(12):1250-1259. https://doi.org/10.1097/DCR.0000000000000924

16. Birkmeyer JD, Stukel TA, Siewers AE, Goodney PP, Wennberg DE, Lucas FL. Surgeon volume and operative mortality in the United States. N Engl J Med. 2003;349(22):2117-2127. https://doi.org/10. 1056/NEJMsa035205

17. Buettner S, Gani F, Amini N, et al The relative effect of hospital and surgeon volume on failure to rescue among patients undergoing liver resection for cancer. Surgery. 2016;159(4):1004-1012. https://doi. org/10.1016/j.surg.2015.10.025 
18. Diaz A, Schoenbrunner A, Pawlik TM. Trends in the geospatial distribution of adult inpatient surgical cancer care across the United States. J Gastrointest Surg. 2019. https://doi.org/10.1007/s11605019-04343-5

19. Birkmeyer JD, Siewers AE, Marth NJ, Goodman DC. Regionalization of high-risk surgery and implications for patient travel times. JAMA. 2003;290(20):2703-2708. https://doi.org/10.1001/jama.290.20.2703

20. The Office of Statewide Health Planning and Development (OSHPD). OSHPD. https://oshpd.ca.gov/data-and-reports/request-data/. Accessed January 10, 2019.

21. ArcGIS. Lesson: network analysis. https://docs.qgis.org/3.4/en/docs/ training_manual/vector_analysis/network_analysis.html. Accessed July 3, 2019.

22. Surgical Volume. Leapfrog. https://www.leapfroggroup.org/ratingsreports/surgical-volume. Published March 20, 2018. Accessed August 15, 2019.

23. Alvino DML, Chang DC, Adler JT, Noorbakhsh A, Jin G, Mullen JT. How far are patients willing to travel for gastrectomy? Ann Surg. 2017;265(6):1172-1177. https://doi.org/10.1097/SLA.00000000000 01826

24. Finlayson SR, Birkmeyer JD, Tosteson AN, Nease RF. Patient preferences for location of care: implications for regionalization. Med Care. 1999;37(2):204-209.

25. Merath K, Chen Q, Diaz A, et al. Local referrals as a strategy for increasing value of surgical care among medicare patients undergoing liver and pancreatic surgery. HPB. 2019. https://doi.org/10.1016/j. hpb.2019.03.371

26. Gani F, Azoulay D, Pawlik TM. Evaluating trends in the volumeoutcomes relationship following liver surgery: does regionalization benefit all patients the same? J Gastrointest Surg Off J Soc Surg Aliment Tract. 2017;21(3):463-471. https://doi.org/10.1007/s11605016-3316-7

27. Smith ME, Nuliyalu U, Dimick JB, Nathan $\mathrm{H}$. Local referral of high-risk pancreatectomy patients to improve surgical outcomes and minimize travel burden. J Gastrointest Surg. 2019. https://doi.org/10.1007/ s11605-019-04245-6

28. Smith ME, Shubeck SP, Nuliyalu U, Dimick JB, Nathan H. Local referral of high-risk patients to high-quality hospitals: surgical outcomes, cost savings, and travel burdens. Ann Surg. 2019. https:// doi.org/10.1097/SLA.0000000000003208

29. Stitzenberg KB, Sigurdson ER, Egleston BL, Starkey RB, Meropol NJ. Centralization of cancer surgery: implications for patient access to optimal care. J Clin Oncol Off J Am Soc Clin Oncol. 2009;27(28):4671. 4678. https://doi.org/10.1200/JCO.2008.20.1715

30. $\mathrm{Xu} Y$, Steckle $\mathrm{S}$, Lui $\mathrm{A}$, et al Effect of proximity to specialty care on outcomes for biliary cancers: a population-based retrospective cohort study. CMAJ Open. 2019;7(1):E131-E139. https://doi.org/10. 9778/cmajo.20180082

31. Jindal M, Zheng C, Quadri HS, et al Why do long-distance travelers have improved pancreatectomy outcomes? J Am Coll Surg. 2017; 225(2):216-225. https://doi.org/10.1016/j.jamcollsurg.2017.04.003

32. Lidsky ME, Sun Z, Nussbaum DP, Adam MA, Speicher PJ, Blazer DG Going the extra mile: improved survival for pancreatic cancer patients traveling to high-volume centers. Ann Surg. 2017;266(2): 333-338. https://doi.org/10.1097/SLA.0000000000001924

33. Dimick JB, Cowan JA, Colletti LM, Upchurch GR. Hospital teaching status and outcomes of complex surgical procedures in the United States. Arch Surg Chic III 1960. 2004;139(2):137-141. https://doi.org/ 10.1001/archsurg.139.2.137

34. Hyder O, Sachs T, Ejaz A, Spolverato G, Pawlik TM. Impact of hospital teaching status on length of stay and mortality among patients undergoing complex hepatopancreaticobiliary surgery in the USA. J Gastrointest Surg Off J Soc Surg Aliment Tract. 2013;17(12):2114-2122. https://doi.org/10.1007/s11605-013-2349-4
35. Beal EW, Mehta R, Tsilimigras DI, et al. Travel to a high volume hospital to undergo resection of gallbladder cancer: does it impact quality of care and long-term outcomes? HPB. 2019;8:pii: S1365. https://doi.org/10.1016/j.hpb.2019.05.004

36. Beal EW, Mehta R, Merath K, et al Outcomes after resection of hepatocellular carcinoma: intersection of travel distance and hospital volume. J Gastrointest Surg Off J Soc Surg Aliment Tract. 2019;23(7): 1425-1434. https://doi.org/10.1007/s11605-019-04233-w

37. Beal EW, Mehta R, Hyer JM, et al Association between travel distance, hospital volume, and outcomes following resection of cholangiocarcinoma. J Gastrointest Surg Off J Soc Surg Aliment Tract. 2019;23(5):944-952. https://doi.org/10.1007/s11605-019-04162-8

38. O'Connor SC, Mogal H, Russell G, et al The effects of travel burden on outcomes after resection of extrahepatic biliary malignancies: results from the US extrahepatic biliary consortium. J Gastrointest Surg Off J Soc Surg Aliment Tract. 2017;21(12):2016-2024. https://doi. org/10.1007/s11605-017-3537-4

39. Idrees JJ, Merath K, Gani F, et al. Trends in centralization of surgical care and compliance with National Cancer Center Network guidelines for resected cholangiocarcinoma. HPB. 2018;21(8):981-989. https://doi.org/10.1016/j.hpb.2018.11.013

40. Muralidhar V, Rose BS, Chen Y-W, Nezolosky MD, Nguyen PL. Association between travel distance and choice of treatment for prostate cancer: does geography reduce patient choice? Int J Radiat Oncol Biol Phys. 2016;96(2):313-317. https://doi.org/10.1016/j.ijrobp. 2016.05.022

41. Lin CC, Bruinooge SS, Kirkwood MK, et al Association between geographic access to cancer care, insurance, and receipt of chemotherapy: geographic distribution of oncologists and travel distance. J Clin Oncol Off J Am Soc Clin Oncol. 2015;33(28):3177-3185. https://doi.org/10.1200/JCO.2015.61.1558

42. Liu E, Santibáñez $P$, Puterman ML, et al A quantitative analysis of the relationship between radiation therapy use and travel time. Int $J$ Radiat Oncol Biol Phys. 2015;93(3):710-718. https://doi.org/10.1016/j. ijrobp.2015.06.004

43. Turrentine FE, Buckley PJ, Sohn M-W, Williams MD. Travel time influences readmission risk: geospatial mapping of surgical readmissions. Am Surg. 2017;83(6):573-582.

44. Cloyd JM, Huang L, Ma Y, Rhoads KF. Predictors of readmission to non-index hospitals after colorectal surgery. Am J Surg. 2017;213(1): 18-23. https://doi.org/10.1016/j.amjsurg.2016.04.006

45. Wasif N, Chang Y-H, Pockaj BA, Gray RJ, Mathur A, Etzioni D. Association of distance traveled for surgery with short- and longterm cancer outcomes. Ann Surg Oncol. 2016;23(11):3444-3452. https://doi.org/10.1245/s10434-016-5242-z

46. Jonathan R, Slotkin MD, Ross OA, Coleman MR, Jaewon Ryu MD, Why GE. Boeing, Lowe's, and Walmart are directly buying health care for employees. Harv Bus Rev. 2017. https://hbr.org/2017/06/why-geboeing-lowes-and-walmart-are-directly-buying-health-care-foremployees. Accessed August 3, 2019.

47. The right care at the right time: expanding our centers of excellence network. Corporate - US. https://corporate.walmart.com/newsroom/ 2016/10/10/the-right-care-at-the-right-time-expanding-our-centersof-excellence-network. Accessed August 3, 2019.

How to cite this article: Diaz A, Burns S, Paredes AZ, Pawlik TM. Accessing surgical care for pancreaticoduodenectomy: Patient variation in travel distance and choice to bypass hospitals to reach higher volume centers. J Surg Oncol. 2019;120:1318-1326. https://doi.org/10.1002/jso.25750 


\section{APPENDIX: ICD 9 and ICD 10 diagnosis and procedure codes}

\section{Pancreatic resection for cancer}

- Diagnosis codes

a. ICD9

- 152 - Malignant neoplasm of small intestine including duodenum.

- 156 - Malignant neoplasm of gallbladder and extrahepatic bile ducts.

- 157 - Malignant neoplasm of pancreas.

b. ICD10

- C23 Malignant neoplasm of gallbladder.

- C240 Malignant neoplasm of extrahepatic bile duct.

- C241 Malignant neoplasm of ampulla of Vater.

- C248 Malignant neoplasm of overlapping sites of biliary tract.

- C249 Malignant neoplasm of biliary tract, unspecified.

- C250 Malignant neoplasm of head of pancreas.

- C251 Malignant neoplasm of body of pancreas.
- C252 Malignant neoplasm of tail of pancreas.

- C253 Malignant neoplasm of pancreatic duct.

- C254 Malignant neoplasm of endocrine pancreas.

- C257 Malignant neoplasm of other parts of pancreas.

- C258 Malignant neoplasm of overlapping sites of pancreas.

- C259 Malignant neoplasm of pancreas, unspecified.

- C170 Malignant neoplasm of duodenum.

- Procedure codes

a. ICD9

- 5252 - distal pancreatectomy.

- 5259 - other partial pancreatectomy.

- 5251 - proximal pancreatectomy.

- 5253 - radical subtotal pancreatectomy/whipple.

- 527 - radical pancreatoduodenectomy.

- 526 - total pancreatectomy.

b. ICD10

- OFTGOZZ - Resection of Pancreas, Open Approach.

- OFTG4ZZ - Resection of Pancreas, Percutaneous Endoscopic Approach. 